\title{
Effects of Natural Aging on Age-Hardening Behavior of Cu-Be-Co and Cu-Ti Alloys Processed by High-Pressure Torsion ${ }^{* 1}$
}

\author{
Chihiro Watanabe ${ }^{1, * 2}$, Masakazu Hibino ${ }^{1, * 3}$, Ryoichi Monzen ${ }^{1}$, Seiichiro $\mathrm{Ii}^{2}$ and Koichi Tsuchiya ${ }^{2}$ \\ ${ }^{1}$ Kanazawa University, Kanazawa 920-1192, Japan \\ ${ }^{2}$ National Institute for Materials Science, Tsukuba 305-0047, Japan
}

\begin{abstract}
The microstructural change and aging behavior of $\mathrm{Cu}-1.8$ mass $\% \mathrm{Be}-0.2 \mathrm{mass} \% \mathrm{Co}$ and $\mathrm{Cu}-3 \mathrm{mass} \% \mathrm{Ti}$ alloys severely deformed by high-pressure torsion (HPT) at room temperature were investigated on two-step aging condition; natural aging and subsequent artificial aging. Application of HPT processing under an applied pressure of $5 \mathrm{GPa}$ for 10 revolutions at $1 \mathrm{rpm}$ to the alloys produced ultra-fine grained structures. The hardnesses of the $\mathrm{Cu}-\mathrm{Be}-\mathrm{Co}$ and $\mathrm{Cu}$-Ti alloys increased with equivalent strain up to 7 , and then saturated to constant values of 400 and $330 \mathrm{Hv}$, respectively. Aging the HPT-processed alloys at $293 \mathrm{~K}$ gradually decreased the resistivities of the alloys; however, even after the longest natural aging period of $2.59 \mathrm{Ms}$ ( 1 month), the hardnesses of the alloys remained essentially unchanged. The attained peak hardness of the $\mathrm{Cu}-\mathrm{Be}-\mathrm{Co}$ alloy on subsequent artificial aging at $593 \mathrm{~K}$ decreased with increasing natural aging time, while the age-hardening behavior of the $\mathrm{Cu}$-Ti alloy during aging at $623 \mathrm{~K}$ was practically unaffected by natural aging at $293 \mathrm{~K}$ up to 2.59 Ms. [doi:10.2320/matertrans.MH201502]
\end{abstract}

(Received March 3, 2016; Accepted March 17, 2016; Published April 22, 2016)

Keywords: $\quad \mathrm{Cu}$-Be-Co alloy, $\mathrm{Cu}$-Ti alloy, high-pressure torsion, age-hardening

\section{Introduction}

Lately, many investigators have examined the aging behavior of age-hardenable alloy systems processed by severe plastic deformation (SPD) technics such as accumulative roll-bonding (ARB) and high-pressure torsion (HPT). Reported aging responses after SPD processing were generally different from alloy to alloy. For example, aging Al-base alloys such as $\mathrm{Al}-\mathrm{Cu}^{1)}, \mathrm{Al}-\mathrm{Mg}-\mathrm{Si}^{2)}$ and $\mathrm{Al}-\mathrm{Ag}^{3)}$ alloys after solution treatment and subsequent SPD processing produced no or only slight amounts of hardening, whereas age-hardenable $\mathrm{Cu}$-base alloys, e.g. $\mathrm{Cu}-\mathrm{Ni}-\mathrm{Be}^{4)}, \mathrm{Cu}-\mathrm{Ni}-\mathrm{P}^{4)}$ and $\mathrm{Cu}-\mathrm{Ni}-$ $\mathrm{Si}^{5)}$ systems, after SPD processing often exhibited larger amounts of age-hardening than the Al-based alloys. However, the cause of the difference in aging responses has not been clarified yet.

Subjecting SPD processes to metallic materials produces not only ultrafine-grained microstructures but also high densities of lattice defects, in particular, very high densities of vacancies. The concentrations of the vacancies are typically close to those of vacancies in thermal equilibrium at the melting points ${ }^{6)}$. Gibicza et al. reported that, during storage of the $\mathrm{SPD}$-processed $\mathrm{Cu}$ even at room temperature (RT), the vacancy concentration reduced significantly, while the dislocation density and the grain size remained unchanged ${ }^{7)}$. Excess vacancy concentrations are well-known to have a strong effect on the precipitation kinetics of second phases ${ }^{8)}$. Therefore, natural aging of age-hardenable alloys after SPD processing should strongly affect the aging responses of the alloys on subsequent artificial aging treatments.

In this study, we investigated the effects of natural aging treatments on the subsequent artificial aging behaviors of $\mathrm{Cu}$ 1.8 mass $\%$ Be- 0.2 mass $\% \mathrm{Co}$ alloy and $\mathrm{Cu}-3$ mass $\% \mathrm{Ti}$ alloy specimens solutionized, and then processed by HPT. G.P.

\footnotetext{
${ }^{* 1}$ This Paper was Originally Published in Japanese in J. JICu 53 (2015) 32-36.

${ }^{* 2}$ Corresponding author, E-mail: chihiro@se.kanazawa-u.ac.jp

${ }^{* 3}$ Graduate Student, Kanazawa University
}

zones first nucleate when the $\mathrm{Cu}-\mathrm{Be}-\mathrm{Co}$ alloy is solutionized, and then aged at around $573 \mathrm{~K}$. The G.P. zones then transforms continuously to the stable $\gamma$ phase via meta-stable phases ${ }^{9)}$. On the other hand, aging the $\mathrm{Cu}$-Ti alloy at around 623 to $773 \mathrm{~K}^{10-12)}$ produces meta-stable $\beta$ ' $-\mathrm{Cu}_{4} \mathrm{Ti}$ phase precipitates via spinodal decomposition.

\section{Experimental Procedure}

This study used a commercial extruded bar of a $\mathrm{Cu}$ $1.8 \mathrm{mass} \% \mathrm{Be}-0.2 \mathrm{mass} \% \mathrm{Co}$ alloy with a diameter of $100 \mathrm{~mm}$, and a commercial hot-rolled sheet of a $\mathrm{Cu}-3$ mass\% $\%$ i alloy with a thickness of $1 \mathrm{~mm}$. Disks with a diameter of $10 \mathrm{~mm}$ and a thickness of $0.8 \mathrm{~mm}$ were cut from the bar and sheet. The disks of the $\mathrm{Cu}-\mathrm{Be}-\mathrm{Co}$ alloy or $\mathrm{Cu}-\mathrm{Ti}$ alloy were solution-treated at $1093 \mathrm{~K}$ for $7.2 \mathrm{Ks}$ or $1273 \mathrm{~K}$ for $7.2 \mathrm{Ks}$, respectively, and then quenched into cold water. The solution-treated disks were subjected to HPT processing under an applied pressure of $5 \mathrm{GPa}$ for 10 rotations with a rotation speed of $1 \mathrm{rpm}$ at RT. The disk specimens were held at $193 \mathrm{~K}$ within $120 \mathrm{~s}$ immediately after the HPT processing. The HPT $\mathrm{Cu}-\mathrm{Be}-\mathrm{Co}$ and $\mathrm{Cu}-\mathrm{Ti}$ specimens were then naturally aged at $293 \mathrm{~K}$ for various periods up to 1 month. Hereafter, specimens naturally aged at $293 \mathrm{~K}$ for $0 \mathrm{~s}, 1$ week $(0.61 \mathrm{Ms})$ and 1 month $(2.59 \mathrm{Ms})$ are referred to as $0 \mathrm{~s}-, 1 \mathrm{w}-$ and $1 \mathrm{~m}$-specimen. Following the natural aging, the $\mathrm{Cu}-\mathrm{Be}-\mathrm{Co}$ and $\mathrm{Cu}-\mathrm{Ti}$ specimens were artificially aged at 593 and $523 \mathrm{~K}$, respectively. The Vickers microhardness was measured along 8 radial directions on the mechanically polished surface of the disk-shaped specimens before and after aging. The measurements of microhardness started at the center of the disks and were taken at every $1 \mathrm{~mm}$ from the disk center to the edge of specimens.

Electrical resistivity measurements were performed by the standard 4-terminal measurement technic at $293 \mathrm{~K}$ using a $\mathrm{DC}$ resistance meter with a constant current of $1 \mathrm{~A}$. The specimens for resistivity measurements were cut into strips with a gage dimension of $0.5^{\mathrm{t}} \times 2.0^{\mathrm{w}} \times 6.0^{1} \mathrm{~mm}^{3}$ from the HPT specimens. The length and width of the strips were measured with 


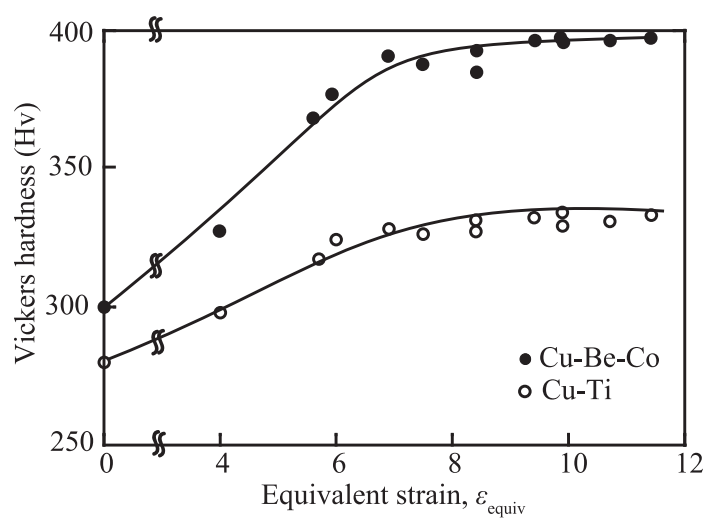

Fig. 1 Change in the Vickers microhardness of $\mathrm{Cu}-\mathrm{Be}-\mathrm{Co}$ and $\mathrm{Cu}-\mathrm{Ti}$ specimens with equivalent strain $\varepsilon_{\text {equiv }}$ introduced by $\mathrm{HPT}$ processing at room temperature (RT) under a compression stress of $5 \mathrm{GPa}$.

a vernier caliper, and the thickness with a micrometer. The center of the strips was at the distance of $3 \mathrm{~mm}$ from the center of the HPT specimens. Terminals of $\mathrm{Cu}$ wires were directly welded on the specimen surface. The accuracy of measurements was approximately a magnitude of $0.001 \mathrm{~m} \Omega$, that is, $0.17 \mathrm{n} \Omega \mathrm{m}$ in resistivity.

Disks with a diameter of $3 \mathrm{~mm}$ were cut from the diskshaped HPT-specimens before and after aging. The center of the 3 -mm disks was at the distance of $3 \mathrm{~mm}$ from the center of the HPT specimens. The 3-mm disks were mechanically ground down to a thickness of $0.2 \mathrm{~mm}$. Thin foils for transmission electron microscopy (TEM) observations were prepared by electro-polishing using a solution of $33 \% \mathrm{HNO}_{3}$ and $67 \%$ of $\mathrm{CH}_{3} \mathrm{OH}$ at $243 \mathrm{~K}$ by applying $6.5 \mathrm{~V}$. TEM observations were performed by a field-emission transmission electron microscope (JEOL, 2010FEF) operated at $200 \mathrm{kV}$.

Lattice constants of the specimens before and after aging were analyzed by X-ray diffraction (XRD) analysis using the $\mathrm{Cu}-\mathrm{K}_{\alpha}$ radiation in a scanning step of $0.02^{\circ}$, and were calculated using the standard $\cos \theta / 2 \theta$ method. The XRD profiles were obtained from a region distance of $3 \mathrm{~mm}$ from the center of HPT specimen.

\section{Results}

\subsection{Microstructure and microhardness after HPT pro- cessing}

Figure 1 shows the Vickers microhardness, plotted against equivalent strain introduced by HPT processing at RT. The equivalent strain $\varepsilon_{\text {equiv }}$ was calculated using the following equation: ${ }^{13)}$

$$
\varepsilon_{\text {equiv }}=\ln \left[\left(2+\gamma^{2}+\gamma \sqrt{4+\gamma^{2}}\right) / 2\right] / \sqrt{3},
$$

where $\gamma$ represents the amount of shear-deformation introduced by HPT and is expressed by

$$
\gamma=2 \pi r N / h \text {. }
$$

Here, $r$ is the distance from the disk center, $N$ is the number of rotations and $h$ is the thickness of the specimen after HPT processing. The microhardnesses of the $\mathrm{Cu}-\mathrm{Be}-\mathrm{Co}$ and $\mathrm{Cu}-\mathrm{Ti}$ specimens increase with increasing equivalent strain up to 7 ,

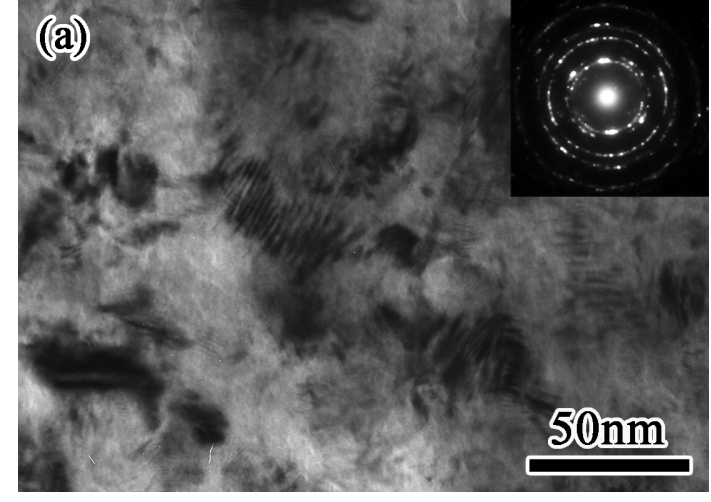

Fig. 2 Bright-field TEM image of a Cu-Be-Co specimen processed by HPT at RT for 10 revolutions under a compression stress of $5 \mathrm{GPa}$. The inset is the corresponding SADP taken using a selected-area aperture having a diameter of $2.5 \mu \mathrm{m}$.

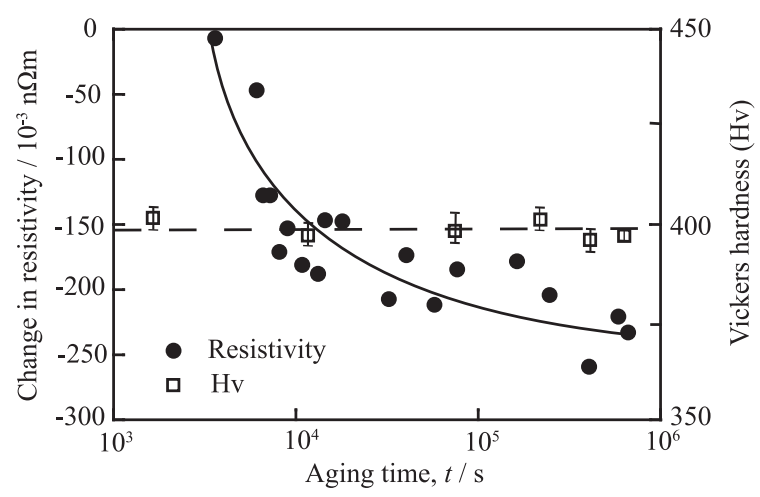

Fig. 3 Change in the Vickers microhardness and resistivity of a $\mathrm{Cu}-\mathrm{Be}-\mathrm{Co}$ specimen processed by HPT during natural aging at $293 \mathrm{~K}$.

and then saturate to constant values of about 400 and $330 \mathrm{Hv}$, respectively.

Figure 2 presents a Bright-field image of the $\mathrm{Cu}-\mathrm{Be}-\mathrm{Co}$ specimen subjected to $10 \mathrm{HPT}$ revolutions. The inset in Fig. 2 is the corresponding selected-area diffraction pattern (SADP) taken using a selected-area aperture having a diameter of $2.5 \mu \mathrm{m}$. An analysis of many dark field images revealed the formation of roughly equiaxed, very fine grains with an average size of approximately $50 \mathrm{~nm}$. The average size of grains in the $\mathrm{Cu}$-Ti specimen subjected to $10 \mathrm{HPT}$ revolutions was approximately $70 \mathrm{~nm}$, slightly larger than that of the $\mathrm{Cu}-\mathrm{Be}-$ Co specimen.

\subsection{Change in resistivity and microhardness during nat- ural aging}

Figures 3 and 4 show the change in the resistivity and microhardness of the $\mathrm{Cu}-\mathrm{Be}-\mathrm{Co}$ and $\mathrm{Cu}-\mathrm{Ti}$ specimens subjected to $10 \mathrm{HPT}$ revolutions during natural aging at $293 \mathrm{~K}$, respectively. The data of microhardness shown in Figs. 3 and 4 were obtained from portions apart from $3 \mathrm{~mm}$ from the center of the HPT specimens. The resistivities of both specimens gradually decreased with increasing natural aging time $t$, whereas the microhardnesses of the specimens exhibited almost no change with $t$. A TEM observation revealed that the grain sizes of both specimens remained essentially unchanged, and that no precipitated phases were formed in the specimens, 


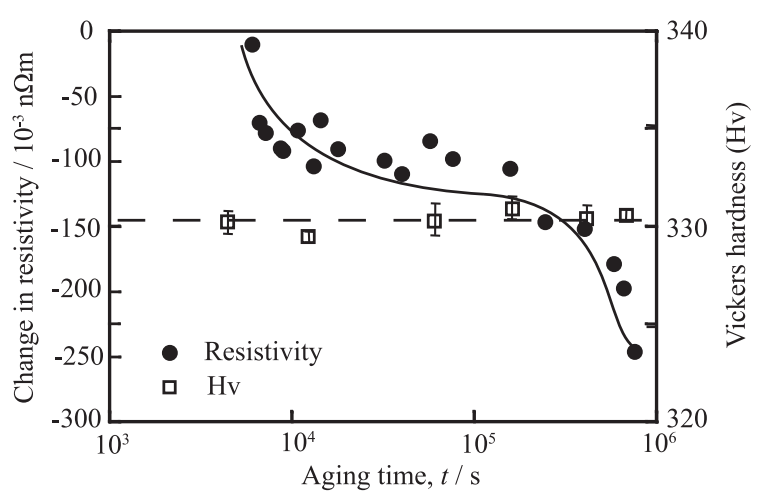

Fig. 4 Change in the Vickers microhardness and resistivity of a $\mathrm{Cu}$-Ti specimen processed by HPT during natural aging at $293 \mathrm{~K}$.

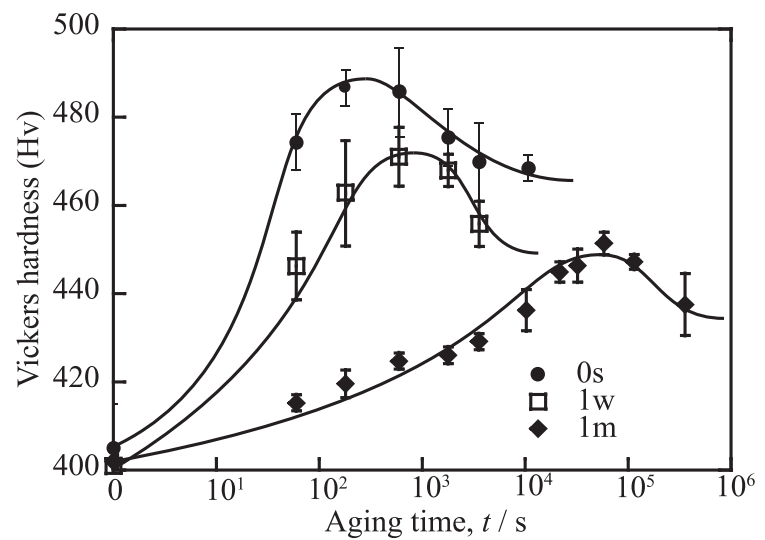

Fig. 5 Age hardening curves of $\mathrm{Cu}-\mathrm{Be}-\mathrm{Co}$ specimens artificially aged at $593 \mathrm{~K}$ after HPT processing and then natural aging for $0 \mathrm{~s}(0 \mathrm{~s}), 1$ week (0.61 Ms; $1 \mathrm{w})$ or 1 month $(2.59 \mathrm{Ms} ; 1 \mathrm{~m})$.

even after the longest period of natural aging $(=2.59 \mathrm{Ms})$.

\subsection{Aging response and microstructure after natural ag- ing}

Figure 5 displays the age-hardening curves of the $\mathrm{Cu}-\mathrm{Be}$ Co specimens during artificial aging at $593 \mathrm{~K}$ for various periods after natural aging for $0 \mathrm{~s}, 1$ week $(0.61 \mathrm{Ms})$ and 1 month $(2.59 \mathrm{Ms})$. The microhardness of each specimen initially increased, eventually attained a peak, and then decreased continuously. It is interesting that, with increasing natural aging time, the peak hardness decreased, and the artificial aging time to attain the peak hardness increased. In contrast, the $\mathrm{Cu}$-Ti specimens did not show any notable change in aging response irrespective of the natural aging time, as shown in Fig. 6.

TEM observations were conducted using the $\mathrm{Cu}-\mathrm{Be}-\mathrm{Co}$ 0s-, $1 \mathrm{w}$ - and 1m-specimens peak-aged at $593 \mathrm{~K}$. Figure 7 exemplifies a bright field TEM image of a grain in the 0s-specimen aged at $593 \mathrm{~K}$ for $180 \mathrm{~s}$. The beam axis is parallel to $[001]_{\mathrm{m}}$ of the $\mathrm{Cu}$ matrix. Finely dispersed, disk-shaped precipitates with an average diameter of about $4 \mathrm{~nm}$, parallel to $(100)_{\mathrm{m}}$ and $(010)_{\mathrm{m}}$ of the Cu matrix, were observed within the grain. According to the literature ${ }^{9)}$, the observed precipitates are determined as G.P. zones consisting of a monolayer Be atoms parallel to $\{001\}_{\mathrm{m}}$ plane. The G.P. zones having nearly identical diameters were also observed in the $1 \mathrm{w}$ - and

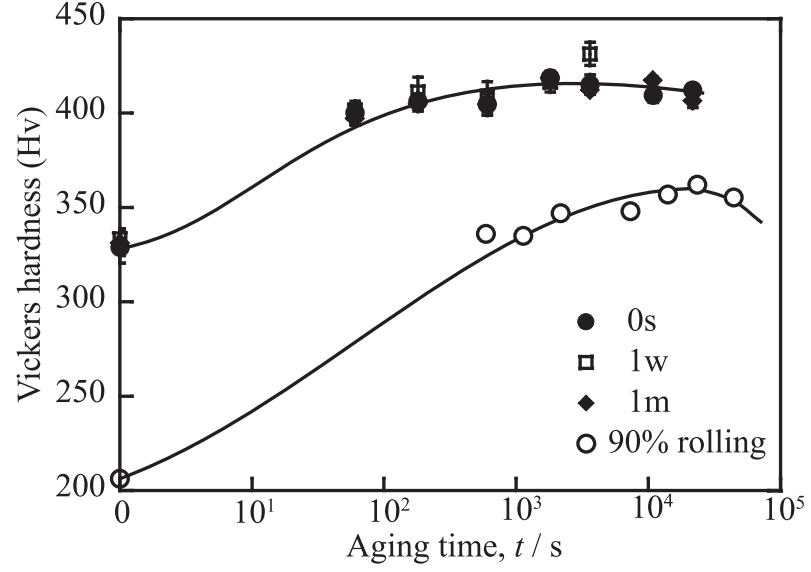

Fig. 6 Age hardening curves of $\mathrm{Cu}$-Ti specimens artificially aged at $623 \mathrm{~K}$ after HPT processing and then natural aging for $0 \mathrm{~s}(0 \mathrm{~s}), 1$ week $(0.61 \mathrm{Ms}$; $1 \mathrm{w})$ or 1 month $(2.59 \mathrm{Ms} ; 1 \mathrm{~m})$.

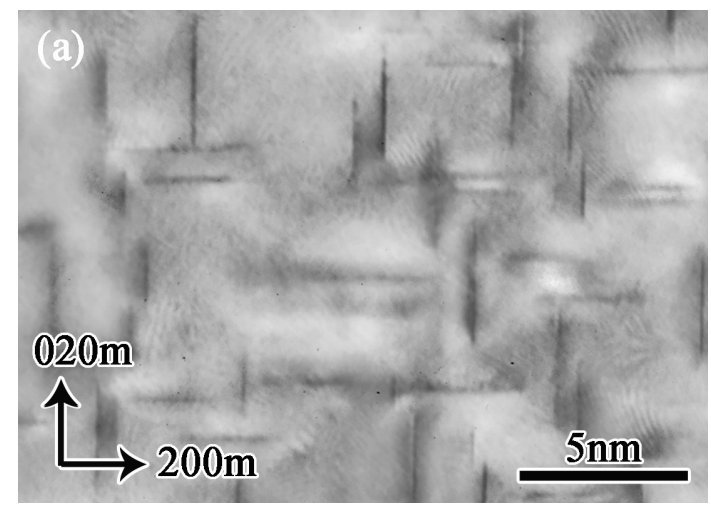

Fig. 7 Bright-field TEM image of disk-shaped G.P. zones in a $\mathrm{Cu}-\mathrm{Be}-\mathrm{Co}$ specimen processed by HPT and then aged at $593 \mathrm{~K}$ for $180 \mathrm{~s}$. The zone axis is parallel to $[001]_{\mathrm{m}}$ of the $\mathrm{Cu}$ matrix.

$1 \mathrm{~m}$-specimens peak-aged at $593 \mathrm{~K}$. Peak-aging all the $\mathrm{Cu}-$ Be-Co specimens at $593 \mathrm{~K}$ did not significantly change their grain sizes, about $50 \mathrm{~nm}$.

Figure 8(a) displays a bright-field image of the $\mathrm{Cu}-\mathrm{Ti}$ 0s-specimen peak-aged at $623 \mathrm{~K}$ for $1.08 \times 10^{4} \mathrm{~s}$. Figures $8(\mathrm{~b})$ and $8(\mathrm{c})$ are the SADP corresponding to Fig. 8(a) and the schematic illustration of Fig. 8(b), respectively. The average grain size was almost unchanged by peak-aging. As can be seen in Fig. 8(a), there exist nearly spherical fine precipitates with an average diameter of approximately $5 \mathrm{~nm}$. Analyses of several SADPs of the precipitates revealed that the precipitates were $\beta^{\prime}-\mathrm{Cu}_{4} \mathrm{Ti}$ phase having $\mathrm{BCT}$ structure ${ }^{10-12)}$. The $\beta$ ' precipitates in the three $\mathrm{Cu}$-Ti specimens peak-aged at $623 \mathrm{~K}$ had almost the same average size of approximately $5 \mathrm{~nm}$.

\section{Discussion}

As described in Section 3.2, the resistivities of both $\mathrm{Cu}-\mathrm{Be}-$ $\mathrm{Co}$ and $\mathrm{Cu}-\mathrm{Ti}$ specimens gradually decreased during natural aging after HPT processing; however, the microhardnesses and grain sizes of both specimens remained almost unchanged even after the longest natural aging time of 1 month (2.59 Ms). Moreover, TEM observations revealed that no precipitation occurred upon natural aging of both specimens. These results 

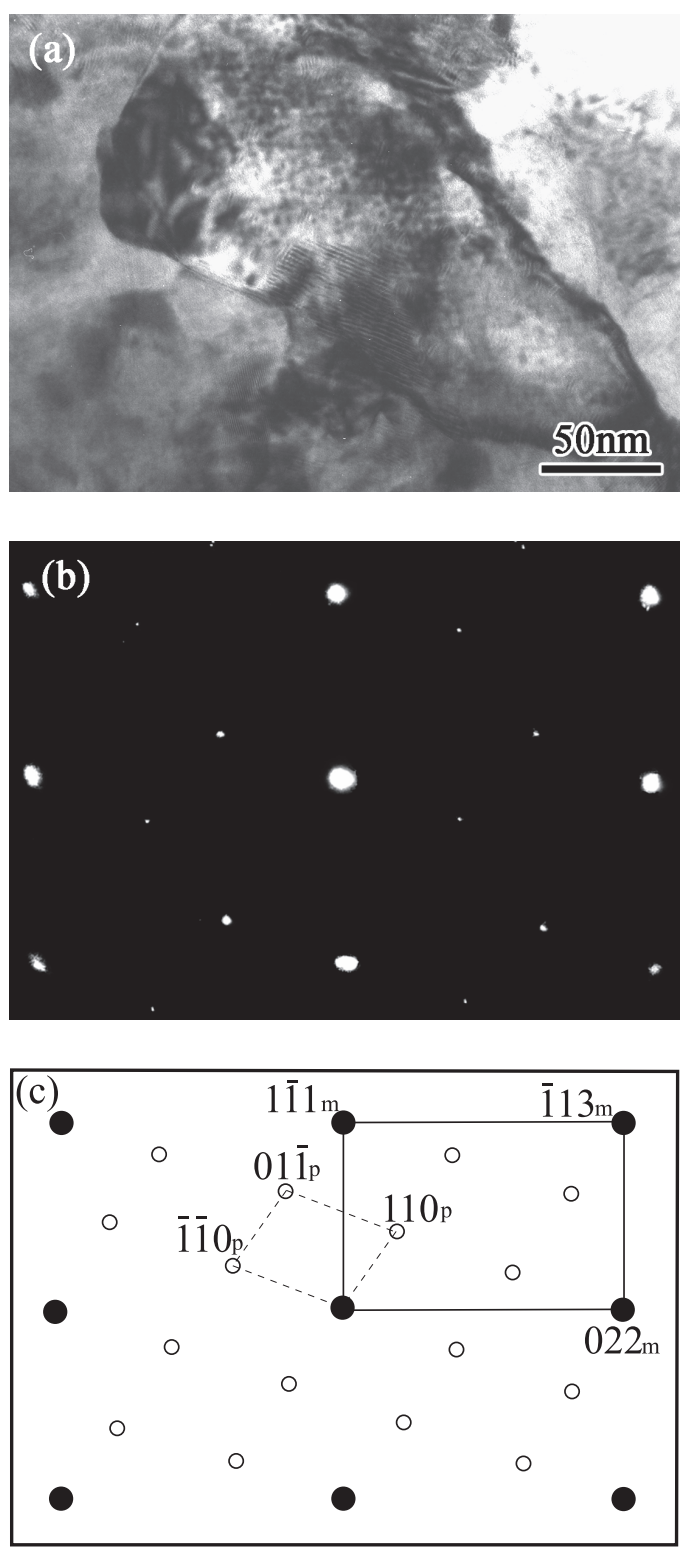

Fig. 8 (a) Bright-Field TEM image taken from a $\mathrm{Cu}$-Ti specimen processed by HPT and then aged at $623 \mathrm{~K}$ for $10.8 \mathrm{Ks}$, (b) SADP corresponding to (a), and (c) schematic illustration of (b).

strongly suggest that recovery of a portion of lattice defects, introduced by HPT processing, occurred during natural aging. Gibicza et al. reported that, during storage of the SPD-processed pure $\mathrm{Cu}$ even at RT, the vacancy concentration decreased significantly while the dislocation density and the grain size remained unchanged ${ }^{7)}$. Although the dislocation densities of the specimens before and after natural aging were not measured, the main contributor to the decrease in resistivity during natural aging (Figs. 3 and 4) seems to be decrease in the vacancy concentration during natural aging, because of significantly smaller contribution to the resistivity by dislocations $\left(\approx 0.8\right.$ to $\left.2.3 \times 10^{-13} \Omega \mathrm{m}^{314}\right)$ than that by a vacancy $\left(=1.5 \times 10^{-6} \Omega\right.$ at $\left.\%^{-115}\right)$.

As shown in Fig. 5, the age-hardening behavior of the $\mathrm{Cu}-$ Be-Co specimen on artificial aging after HPT processing and subsequent natural aging is strongly affected by the period of natural aging. It is widely known that the concentration of vacancies strongly influences the nucleation of precipitates.
Table 1 Lattice parameters $a$ of $\mathrm{Cu}$ matrix and volume fractions $f$ of G.P. zones for $\mathrm{Cu}-\mathrm{Be}-\mathrm{Co}$ specimens processed by HPT (as HPT) and $\mathrm{Cu}-\mathrm{Be}$ Co specimens peak-aged at $593 \mathrm{~K}$ after HPT processing and subsequent natural aging for $0 \mathrm{~s}(0 \mathrm{~s}), 1$ week $(0.61 \mathrm{Ms} ; 1 \mathrm{w})$ or 1 month $(2.59 \mathrm{Ms}$; $1 \mathrm{~m})$.

\begin{tabular}{ccc}
\hline Specimen & $a(\mathrm{~nm})$ & $f$ \\
\hline As HPT & 3.6280 & - \\
\hline $0 \mathrm{~s}$ & 3.6128 & 0.080 \\
\hline $1 \mathrm{w}$ & 3.6135 & 0.076 \\
\hline $1 \mathrm{~m}$ & 3.6138 & 0.074 \\
\hline
\end{tabular}

Generally speaking, the nucleation rate of precipitates increases with increasing excess vacancies ${ }^{8)}$. It can thus be said that the initial age-hardening rate of the $\mathrm{Cu}-\mathrm{Be}-\mathrm{Co}$ specimens on the artificial aging decreases with increasing natural aging time, since the vacancy concentration decreases as the natural aging time increases.

Ota et $a l$. reported that the precipitation strengthening by G.P. zones is controlled by the precipitate shearing mechanism ${ }^{16)}$. According to the shearing mechanism, the amount of precipitation strengthening $\Delta \sigma$ is expressed as ${ }^{17)}$

$$
\Delta \sigma \propto \sqrt{\bar{r} f}
$$

where $\bar{r}$ is the average size of precipitates and $f$ is the volume fraction of precipitates. As described in Section 3.3, the average diameters of G.P. zones are nearly identical in the three $\mathrm{Cu}-\mathrm{Be}-\mathrm{Co}$ specimens peak-aged at $593 \mathrm{~K}$ after natural aging for three different periods. Therefore, the differences in the amount of age-hardening between the three specimens can be discussed by estimating $f$. To obtain values of $f$ of G.P. zones, the lattice constants $a$ of the three specimens before and after natural aging and subsequent peak-aging were measured using XRD technic. The measured lattice constants are listed in Table 1 . The values of $f$ were determined by applying the measured lattice constants to the experimental data regarding the dependence of the lattice constant on the Be concentration in the literature $\left(\approx-3.17 \times 10^{-11} \mathrm{~m} \text { at } \%^{-1}\right)^{18)}$. The diskshaped G.P. zones are assumed to have a thickness of $0.226 \mathrm{~nm}$, equal to the diameter of Be atoms ${ }^{19)}$. The calculated values of $f$ are also summarized in Table 1 . The value of $f$ decreases with increasing natural aging time. This explains why the amount of age-hardening by artificial peak-aging decreases with increasing natural aging time. It seems that the volume fraction of G.P. zones decreases with increasing natural aging time, since the nucleation rate of G.P. zones decreases as the vacancy concentration decreases. In addition, the growth rate of G.P. zones should also be affected by the vacancy concentration. Thus, it calls for further study on the effects of natural aging on the growth kinetics of G.P. zones.

As shown in Fig. 6, in contrast to the results of $\mathrm{Cu}-\mathrm{Be}-\mathrm{Co}$ specimens (Fig. 5), the difference in natural aging period does not essentially affect the age-hardening behavior of the $\mathrm{Cu}$-Ti specimens on subsequent artificial aging. As discussed above, the change in vacancy concentration by natural aging strongly influences the age-hardening behavior of the $\mathrm{Cu}-\mathrm{Be}$ Co specimens, since a nucleation process is necessary for the formation of G.P. zones. On the other hand, the $\beta$ ' precipitates responsible for age-hardening of the $\mathrm{Cu}-\mathrm{Ti}$ specimens were formed via spinodal decomposition ${ }^{10-12)}$ without nucleation 
process. Thus, it can be said that the age-hardening behavior of the $\mathrm{Cu}$-Ti specimens is not influenced by the natural aging. An age-hardening curve of the present $\mathrm{Cu}$-Ti alloy aged at $623 \mathrm{~K}$ after solution treatment at $1273 \mathrm{~K}$ and subsequent cold-rolling to a reduction of $90 \%$ in thickness is also shown in Fig. 7. There are little differences in the amount of age-hardening at peak-aging and the aging time to attain the peak hardness between the HPT and the 90\% rolling specimens. In the $\mathrm{Cu}-\mathrm{Ti}$ alloy, prior mechanical processing (HPT or cold-rolling) and natural aging time have small impact on the age-hardening behavior of the alloy.

\section{Conclusions}

Our investigation of the effects of prior natural aging on the subsequent artificial aging behavior of $\mathrm{Cu}-1.8$ mass $\% \mathrm{Be}-$ 0.2 mass \% Co and $\mathrm{Cu}-3$ mass\% $\%$ i alloys severely deformed by high-pressure torsion (HPT) yielded the following conclusions:

(1) The resistivities of both alloys processed by HPT decrease with increasing natural aging time; however, the microhardnesses of the alloys are almost unchanged even after the longest natural aging time of $2.59 \mathrm{Ms}$. The decrease in resistivity of the alloys can be ascribed to decrease in the excess vacancies introduced by the HPT processing during natural aging.

(2) On artificial aging at $593 \mathrm{~K}$ of the $\mathrm{Cu}-\mathrm{Be}-\mathrm{Co}$ alloy after natural aging, the attained peak-hardness decreases and the aging time till peak-hardness increases as natural aging time increases. However, natural aging time does not essentially affect the age-hardening behavior of the $\mathrm{Cu}-\mathrm{Ti}$ alloy on subsequent artificial aging.

(3) The difference in the effects of natural aging on subsequent artificial aging behavior between the two alloys are associated with the different formation mechanisms of strengthening precipitates, that is, direct formation of G.P. zones in the $\mathrm{Cu}-\mathrm{Be}-\mathrm{Co}$ alloy and formation of $\beta^{\prime}-\mathrm{Cu}_{4} \mathrm{Ti}$ phase in the
$\mathrm{Cu}$-Ti alloy via spinodal decomposition.

\section{Acknowledgements}

This work was partially supported by a Grant-in-Aid for Scientific Research on Innovative Areas, "Bulk Nanostructured Metals”, through MEXT, Japan, Contract No. 22102002. C. Watanabe would also like to acknowledge the financial support of the Grant-in-Aid for Science Research (C), Grant No. 25420775.

\section{REFERENCES}

1) N. Tsuji, T. Iwata, M. Sato, S. Fujimoto and Y. Minamino: Sci. Technol. Adv. Mater. 5 (2004) 173-180.

2) Y. Huang, J.D. Robson and P.B. Prangnell: Acta Mater. 58 (2010) 1643-1657.

3) K. Ohashi, T. Fujita, K. Kaneko, Z. Horita and T.G. Langdon: Mater. Sci. Eng. A 437 (2006) 240-247.

4) R. Monzen, Y. Takagawa, C. Watanabe, D. Terada and N. Tsuji: Procedia Eng. 10 (2011) 2417-2422.

5) Y. Takagawa, Y. Tsujiuchi, C. Watanabe, R. Monzen and N. Tsuji: Trans. JIM 54 (2013) 1-8.

6) M.J. Zehetbauer, G. Steiner, E. Schafler, A. Karznikov and E. Koznikova: Mater. Sci. Forum 503-504 (2006) 57-64.

7) J. Gubicza, S.V. Dobatkin, E. Khosravi, A.A. Kuznetsov and J.L. Labar: Mater. Sci. Eng. A 528 (2011) 1828-1832.

8) K.C. Russell: Scr. Metall. 3 (1969) 313-316.

9) R. Monzen, T. Seo, T. Sakai and C. Watanabe: Trans. JIM 47 (2006) 2925-2934.

10) A. Datta and W.A. Soffa: Acta Metall. 24 (1976) 987-1001.

11) D.E. Laughlin and J.W. Cahn: Acta Metall. 23 (1975) 32037.

12) W.A. Soffa and D.E. Laughlin: Prog. Mater. Sci. 49 (2004) 347-366.

13) S. Onaka: J. Japan Inst. Metals 74 (2010) 165-170.

14) A.S. Karolik and A.A. Luhvich: J. Condens. Mater. 6 (1994) 873-886.

15) F.J. Blatt: Phys. Rev. 99 (1955) 1708-1716.

16) S. Ota, N. Muramatu, K. Sengoku, C. Watanabe and R. Monzen: J. Jpn. Soc. Mater. Sci. 56 (2007) 531-536.

17) V. Gerold and H. Haberkorn: Phys. Status Solidi 16 (1966) 675-684.

18) H. Tanimura and G. Wassermann: Z. Metallk. 25 (1933) 179-181.

19) The Japan Institute of Metals: Kinzoku Data Book 3rd Ed. (Maruzen, Tokyo 1993). 